\title{
TECHNICAL PROBLEMS OF THE EXPANSION OF TELEVISION IN BRITAIN
}

$I^{\mathrm{N}}$ October 1952 the Postmaster General set up a Television Advisory Committee, charged primarily with the task of advising on the development of television and sound broadcasting in Great Britain at frequencies greater than $30 \mathrm{Mc} . / \mathrm{s}$. , and the Committee has now published its first report*. This is an important document, for it lays bare the basic technical difficulties of completing the present singleprogramme network in Great Britain to cover almost completely the whole of the country and of building up another network (or networks) with allowance in the frequency spectrum for the possible extension of the programmes to colour. These difficulties are not insuperable, but they do present problems the existence of which the non-technical public is possibly unaware, and probably the biggest factor operating against their solution is not the technical one but that of finance. In the present controversy that is brewing in Great Britain on the establishment of commercial radio and television in competition with the present monopoly of the B.B.C., these technical difficulties and their inherent financial consideration should not be overlooked.

Besides television there is the problem of higherfrequency sound broadcasting, such as frequencymodulation transmissions, a development which has not made much progress in Britain (probably owing to the excellence of the present amplitude-modulation system and the efficacy of using medium-waves to cover a relatively small island situated in temperate latitudes); nevertheless, if the present service is to be improved and further programmes developed, the experience of other countries indicates that this is a matter which will have to be taken up, and the Committee specifically states that it will be the subject of a future report.

The nature of television requires high carrierfrequencies, and under international agreement the frequency bands allotted for television (and higherfrequency sound broadcasting) are five in number, as follows: (1) 41-68 Mc./s.; (2) $87.5-100 \mathrm{Mc} / \mathrm{s} . ;$ (3) 174-216 Mc./s.; (4) 470-585 Mc./s.; and (5) 610-960 Mc./s. Bands I-3 are generally known as 'very high frequencies' (V.H.F.), and Bands 4-5 as 'ultra high frequencies' (U.H.F.). A Technical Sub-Committee under the chairmanship of Dr. W. G. Radley, engineer-in-chief of the General Post Office, and composed of nine other members drawn from the Post Office, the B.B.C., the radio industry, the Department of Scientific and Industrial Research and the University of London, was set up to consider these bands, and their conclusions form the basis of the present report.

Assuming the continuation of the B.B.C.'s 405-line system, a monochrome television programme requires a channel-width of $5 \mathrm{Mc}$./s. On this basis, Band 1 is scheduled to be completely used up in supplying the present B.B.C. service to $90-95$ per cent of the population of Great Britain (at the time of the report about 78 per cent was covered). Band 2 is too narrow to be of much use for television, and it is proposed that it should be left for the provision of additional sound services. * General Post Office. First Report of the Television Advisory
Committee, 1952. Pp. 14+4 maps. (London: H.M.S.O., 1953.) 18. $6 d$. net.
Band 3 will accommodate eight channels and is very suitable for television. Unfortunately an arrangement has already been made in Great Britain whereby the part of the band between 174 and $210 \mathrm{Mc} / \mathrm{s}$. could be used for private communication and broadcasting services, so that $a$ number of business firms and other organizations are, in fact, using equipment within these frequencies; and further to this, on an international level, a number of radio navigational services have been set up in the other part of the band, between 200 and $216 \mathrm{Mc} . / \mathrm{s}$. At the moment the only part of Band 3 that could be immediately used for television are two channels situated in the range 184-195 Mc./s. On the basis of these two channels being used for a second television programme, it would only be possible to set up three or four high-power stations situated in densely inhabited areas, and this would cover not much more than half the total population. The Committee therefore strongly recommends that a third channel be made available in Band 3 (or adjacent to Band 3 ) so that 70 per cent of the population can be served, and it also emphasizes the eventual necessity of clearing the whole band, though this will cause considerable expense because of the existing equipment already operating on these frequencies.

In Bands 4 and 5 it is recommended that any possible allocation should be done on the basis of every third 5-Mc./s. channel, so as to provide room adjacent to each channel for broadcasting the additional signal information that will be necessary for a programme in colour ; in this connexion, the Committee is of the opinion that any extension of a television programme to colour should only be done in such a manner that existing sets can continue to receive the programme in monochrome. The preliminary recommendation for Bands 4 and 5 are that allocations should not go beyond $700 \mathrm{Mc} . / \mathrm{s}$, and thus, in all, provision can be made for about fifty stations. The trouble with Bands 4 and 5 compared with Band 3 is that they require a minimum fieldstrength for reasonable reception of about $3 \mathrm{mV} . / \mathrm{m}$. as against $0 \cdot 3-0.5 \mathrm{mV} . / \mathrm{m}$. for the latter, and therefore to cover a given area at the higher frequencies requires relatively many more transmitters. In addition, the receiving equipment will cost more, particularly adaptors for converting the signal to lower frequencies that can be handled by sets working at the existing frequencies ; in fact, it can generally be said that a great deal of work remains to be done in the development of cheap mass-produced valves, circuits and aerials for the higher frequencies on the same scale as has already been done for components operating at existing lower frequencies.

The last part of the Committee's report deals with general considerations, some of them rather tentative, of the various claims for frequencies that may be, or have been, made by various interests, and the different ways that these claims can best be met. To complete the report, there are four folding maps of Great Britain, the headings of which indicate the information that they give : the possible use of two channels from Band 3 for television stations; estimated coverage planned by the B.B.C. for their first television programme; estimated coverage planned by the B.B.C. for a second television programme assuming 
the use of six channels in Band 3; and competitive television-approximate transmitter sites and powers as requested by various applicants for licences.

Some of the detailed matter raised in the last part of the report will obviously cause controversy. For example, there is the question of whether the B.B.C. should be granted its request to set up low-power stations on the two free frequencies in Band 3 so as to complete its present national programme or whether it should be forced to use either Band 1 (if this is technically possible) or Bands 4 and 5 . Then, as already mentioned, who is to have these two channels for the high-power transmission of a second programme to cover the densely populated regions of Britain, and should this be immediately supplemented by a third channel ? From this, one is led. to the problem of freeing completely the whole of Band 3 ; but if television is going to make considerable headway in Britain, even this is not enough, and serious attention will obviously have to be paid to Bands 4 and 5.

Some persons may feel that the actual developments which have taken place so far are such that all this speculation is rather nebulous and that to introduce at this juncture some licensing authority armed with strong powers would be premature because the economic state of Britain in the present conditions of world tension will effectively prevent rapid expansion for many years to come. However, this point of view is refuted by one member of the Committee who, in a minority report, points out that we are already near the point of actually using Band-3 frequencies for a television programme; but because various organizations have been allowed channels on this band for their own private purposes, it is effectively used up, and much money will have to be expended to move them to other frequenciesa financial liability which apparently neither the State nor the organizations concerned are showing much inclination to shoulder.

All this points to the fact that perhaps it would be best in the long run for all concerned if some sort of policy could be formulated now and put in the hands of an effective authority so that the frequency spectrum, which, it seems, is all too small, can be economically shared out in a manner that generally meets with public approval.

\section{AMERICAN PHYSICAL SOCIETY AND THE AMERICAN ASSOCIATION OF PHYSICS TEACHERS}

\section{ANNUAL MEETING}

$\mathrm{T}$ HE 1953 annual meeting of the American Physical Society and the twenty-second annual meeting of the American Association of Physics Teachers were held simultaneously at Harvard University, Cambridge, Mass., during January 22-24. In spite of the change of venue from New York City where the past annual meetings had been held, the meetings were well attended with a registration of 1,833 and with more than three hundred ten-minute papers, in addition to longer invited ones, contributed to the various sessions of the two bodies.

At the joint ceremonial session during the afternoon of January 23 , the retiring presidential address of the Society was delivered by Prof. J. H. Van
Vleck (Harvard University), who took as his subject "Two Barrier Phenomena". In this address he first discussed the barrier which current immigration policies of the United States raises to the entry of visiting foreign scientists, and then described the various theoretical developments which have been required in order to keep pace with the experimental advances in the microwave spectroscopy of ammonia. The Oersted Medal of the Association was presented to Prof. R. M. Sutton (Haverford College), who responded by discussing the heritage of a physics teacher ${ }^{1}$, and the eleventh Richtmyer Memorial Lecture was delivered by Prof. E. M. Purcell (Massachusetts Institute of Technology), who took as his subject "Nuclear Magnetism". The after-dinner speaker at the banquet in the evening was Prof. J. A. Stratton (Massachusetts Institute of Technology), who gave an outstanding address on thoughts on technical education stimulated by a visit to Britain, in which he compared education in Great Britain and the United States.

The banquet was also the occasion of the presentation of the first O. E. Buckley Solid-State Physics Prize to Dr. W. Shockley, research physicist at the Bell Telephone Laboratories, for his contributions to semiconductor research. The prize (1,000 dollars), which is administered by a committee of the Physical Society, was established in 1952 under an endowment of a 50,000-dollar trust fund provided by Bell Telephone Laboratories in honour of the Laboratories' former president, O. E. Buckley, who retired recently after thirty-eight years in administrative and scientific posts with the Bell System.

At the business meeting of the Society the following were elected to hold office for 1953 : President, E. Fermi ; Vice-President, H. A. Bethe; Secretary, K. K. Darrow ; and Treasurer, G. B. Pegram. A welcome abatement in the rate of expansion of the Physical Review was reported by the managing editor, and the treasurer indicated that the present satisfactory position did not call for any further change in the dues and charges.

The twenty-eight invited papers contributed at the scientific sessions of the Physical Society included : a group of three papers by members of the Brookhaven National Laboratory describing new and prospective accelerators at the Laboratory; a separate session in which P. W. Bridgman, G. R. Harrison, G. F. Hull and E. C. Pollard delivered papers dealing with, respectively, recent results at high pressures, échelle spectroscopy, experimental discoveries announced in the programme of the meeting of fifty years ago, and physical studies of viruses; at the symposium of the Division of Electron Physics, individual contributions by M. O'Day (Air Force Cambridge Research Centre) on electron physics in the upper atmosphere, and M. S. Livingston (Massachusetts Institute of Technology and the Brookhaven Laboratory) on the strong-focusing synchrotron; and at the symposium of the Division of Fluid Dynamics, papers on turbulent flow and on phenomena at supersonic speeds. Solid-state physics was represented by contributions by J. A. Hornbeck (Bell Telephone Laboratories) on semiconductors, and P. D. Johnson (General Electric Co.) on luminescence in solids; and in addition to that by $\mathrm{F}$. Bitter on magneto-resonance and magnetic optics; there were several papers dealing with paramagnetic resonance and nuclear resonance. G. Lindström (Nobel Institute of Physics) discussed the establishment of an absolute energy scale in beta-ray spectro- 